\title{
Analysis of the Radiation from a Complex Multi-Conductor Transmission Line
}

\author{
F. Hassoun ${ }^{1}$, G. Bousaleh author ${ }^{2}$ and R. Hage Chehade ${ }^{2}$. \\ 1 France Telecom R\&D - France \\ 2 Lebanese University- IUT Saida - Lebanon \\ e-mail: gbousaleh@hotmail.fr
}

\begin{abstract}
The Deployment of Power Line Transmission (PLT) and the development of new broadband services over the telephone network through technology like xDSL (x Digital Subscriber Line), requires higher data rates, consequently higher bandwidths, and operating frequencies. So it is generally accompanied with electromagnetic compatibility (EMC) phenomena, in particular the radiated emissions associated to the deployed system and used cables characteristics. In fact the electrical cable presents variations in their geometry, causing an increase in the electromagnetic radiation. This paper presents a theoretical approach to study a complex transmission line network over ground plane. This approach leads to an analytical expression for the evaluation of P.U.L. parameters of finite length twisted wires lines. These expressions give the capacitances and the inductances values in every point of the cable, the theoretical results are compared to measurements.

The formalism is also derived to determine the distribution of the electromagnetic field radiated by Shielded or Unshielded Twisted Pair cables with discontinuity. The obtained results are compared to those provided by a code based on the antenna theory.
\end{abstract}

\section{Keywords}

PLT, xDSL, radiated emissions, nonuniform transmission line, discontinuity, P.U.L. parameter.

\section{Introduction}

The advance of high-speed systems increases the generation and radiation of undesired electromagnetic waves. For example, as the demand and deployment of multi-media data transmission are increasing, xDSL technology is widely used on the telecommunication access network. Conveying such services requires higher data rates, consequently higher bandwidths, and operating frequencies.

The increase in bandwidth for the new services will require considerable ingenuity. In particular, signal propagation at these frequencies through the differential and common mode, lead not only to ground wave transmission but also to sky wave propagation.

To study cable systems and the resulting electromagnetic phenomena, generally we use the antenna theory or the transmission line theory. In the first case, the integral equations resulting from the Maxwell's equations are used, which allows to study complex structures more rigorously than the transmission line theory. However, such approach needs an important computing time according to the complexity of the studied configuration.

With the transmission line theory, the effectiveness of the method depends on the Per-Unit-length parameters
(P.U.L.), related to the elementary structures of the equivalent model. These parameters can be calculated or measured.

For telecommunication, the twisted pair cables are frequently used. The symmetry of telecommunication cables is directly depending on the electrical characteristic of the twist. This symmetry can give rise to common mode currents at any point on the network and generates radiated emissions. The P.U.L. parameters are strongly related to the geometry of the studied structure. Consequently, a network constituted of twisted pair cables is more difficult to model.

On the other hand, discontinuities in the transmission line like bends may cause disturbing fields and consequently, increase the crosstalk and the electromagnetic interferences.

In this paper, we propose an approach for modelling transmission line localized over a ground plane. Section II and III presents the formalism, which has been used in order to determine the P.U.L. parameters of twisted pair cables above a perfect ground plane. In section IV, the approach is used to study the electromagnetic emission from transmission line network with discontinuity (bend, variable height of different sections). This characterization leads to the determination of the current and voltage distribution by using chain matrix approach. The following step is the determination of electromagnetic field radiated by Shielded or Unshielded Twisted Pair (U.T.P. or S.T.P.) cables.

\section{Theoretical approach}

The formulation proposed in this paper leads to study the distribution of electromagnetic field radiated by multi-conductor network of complex geometry. The formalism is based on the non-uniform transmission line theory, where the P.U.L. parameters vary according to the geometry of the line $[7,8]$. The transmission line equations can be derived from the integral or differential Maxwell's equations. To assess the P.U.L. parameters, The calculation of the magnetic field and the electric charges are necessary [1,2]. From the Maxwell's equations, the electric field can be obtained via the scalar and vector potentials:

$$
\overrightarrow{\mathrm{E}}=-\nabla \phi-j \omega \overrightarrow{\mathrm{A}}, \quad \overrightarrow{\mathrm{H}}=\frac{1}{\mu} \nabla \times \overrightarrow{\mathrm{A}}
$$

With, 
$\phi(\overrightarrow{\mathrm{r}})=-\frac{1}{4 \pi \mathrm{j} \omega \varepsilon} \int_{\mathrm{V}} \mathrm{G}\left(\overrightarrow{\mathrm{r}}, \overrightarrow{\mathrm{r}}^{\prime}\right) \nabla^{\prime} \cdot \overrightarrow{\mathrm{J}}\left(\overrightarrow{\mathrm{r}}^{\prime}\right) \mathrm{d} \mathrm{V}^{\prime}$

$\overrightarrow{\mathrm{A}}(\overrightarrow{\mathrm{r}})=-\frac{\mu}{4 \pi} \int_{\mathrm{V}} \overrightarrow{\mathrm{J}}\left(\overrightarrow{\mathrm{r}}^{\prime}\right) \mathrm{G}\left(\overrightarrow{\mathrm{r}}, \overrightarrow{\mathrm{r}}^{\prime}\right) \mathrm{d} V^{\prime}$

$\vec{J}\left(\vec{r}^{\prime}\right)$ is the current density, $G\left(\vec{r}, \vec{r}^{\prime}\right)$ is Green's function in free space. $\mu$ and $\varepsilon$ represent respectively the permeability and the permittivity in the free space. The effect from the infinite ground plane is incorporated in $G\left(\vec{r}, \vec{r}^{\prime}\right)$.

$\mathrm{G}\left(\overrightarrow{\mathrm{r}}, \overrightarrow{\mathrm{r}}^{\prime}\right)=\frac{\exp (-\mathrm{jKR})}{\mathrm{R}}, \mathrm{R}=\left|\overrightarrow{\mathrm{r}}-\overrightarrow{\mathrm{r}}^{\prime}\right|, \mathrm{K}=\sqrt{\varepsilon \mu}$

The current density $|\mathrm{J}|$ and charges density $\rho$ are obtained by the following equation : $\operatorname{div} \cdot \vec{J}=-j \omega \rho$.

The tangential component of the electric field on the conductor surface vanish, $\overrightarrow{\mathrm{E}}=0 \Rightarrow \nabla \phi=-\mathrm{j} \omega \overrightarrow{\mathrm{A}}$. Denote $\hat{\mathrm{Z}}$ as the unit tangential vector on the conductor surface.

$\hat{\mathrm{z}} \bullet \nabla \phi(\overrightarrow{\mathrm{r}})=-\frac{\mathrm{j} \omega \mu}{4 \pi} \int_{\mathrm{V}} \hat{\mathrm{z}} \bullet \overrightarrow{\mathrm{J}}\left(\overrightarrow{\mathrm{r}}^{\prime}\right) \mathrm{G}\left(\overrightarrow{\mathrm{r}}, \overrightarrow{\mathrm{r}}^{\prime}\right) \mathrm{d} V^{\prime}: \overrightarrow{\mathrm{r}} \in \mathrm{S}$

Using the thin-wire approximation [3], i.e. the currents on wire of small diameters will circulate only on the axis of the conductor $\mathrm{C}_{\mathrm{i}}$ where $\mathrm{i}=0,1 \ldots \mathrm{N}(\mathrm{N}$ : number of conductors). Note $\mathrm{I}_{\mathrm{i}}\left(\mathrm{z}^{\prime}\right)$ the total current on the conductor $\mathrm{C}_{\mathrm{i}}, \mathrm{z}^{\prime}$ corresponds to the co-ordinates on the axis of each conductor. $\phi_{\mathrm{i}}(\mathrm{z})$ represent the scalar potential on $\mathrm{C}_{\mathrm{i}}$, which is contributed from all other conductors. $\mathrm{z}$ indicates the observation's point and it is located on the surface of the conductor.

$\phi_{\mathrm{i}}(\mathrm{z})=-\frac{1}{4 \pi \mathrm{j} \omega \varepsilon} \sum_{\mathrm{n}=1}^{\mathrm{N}} \int_{\mathrm{C}_{\mathrm{n}}} \frac{\mathrm{d}_{\mathrm{n}}\left(\mathrm{z}^{\prime}\right)}{\mathrm{d} z^{\prime}}\left[\mathrm{G}_{\mathrm{in}}\left(\mathrm{z}, \mathrm{z}^{\prime}\right)-\mathrm{G}_{\mathrm{i} 0}\left(\mathrm{z}, \mathrm{z}^{\prime}\right)\right] \mathrm{d} \mathrm{z}^{\prime}$

$\frac{\mathrm{d} \phi_{\mathrm{i}}(\mathrm{z})}{\mathrm{dz}}=-\frac{\mathrm{j} \omega \mu}{4 \pi} \sum_{\mathrm{n}=1}^{\mathrm{N}} \int_{\mathrm{C}_{\mathrm{n}}} \mathrm{I}_{\mathrm{n}}\left(\mathrm{z}^{\prime}\right) \hat{\mathrm{z}} \bullet \hat{\mathrm{z}}^{\prime}\left[\mathrm{G}_{\mathrm{in}}\left(\mathrm{z}, \mathrm{z}^{\prime}\right)-\mathrm{G}_{\mathrm{i} 0}\left(\mathrm{z}, \mathrm{z}^{\prime}\right)\right] \mathrm{d} \mathrm{z}^{\prime}$

The voltage for $\mathrm{m}$-th conductor is calculated by:

$\mathrm{V}_{\mathrm{m}}(\mathrm{z})=\phi_{\mathrm{m}}(\mathrm{z})-\phi_{0}(\mathrm{z}), \quad \mathrm{m}=0,1, \ldots \mathrm{N}$

On the other hand, we can deduce :

$\frac{d \vec{V}(z)}{d z}=-j \omega \overrightarrow{\mathrm{LI}}(\mathrm{z}), \quad \frac{\mathrm{d} \overrightarrow{\mathrm{I}}(\mathrm{z})}{\mathrm{dz}}=-j \omega \overline{\mathrm{C}} \overrightarrow{\mathrm{V}}(\mathrm{z})$

$\mathrm{V}$ and I respectively represent the current and the voltage for each conductor to the reference conductor (vector of $\mathrm{N}$ values). $\overline{\mathrm{L}}=\left[\mathrm{l}_{\mathrm{mn}}\right]$ and $\overline{\mathrm{C}}=\overline{\mathrm{B}}^{-1}=\left[\mathrm{b}_{\mathrm{mn}}\right]^{-1}$ are $\mathrm{NxN}$ matrices $(\mathrm{m}, \mathrm{n}=1,2 \ldots \mathrm{N}) . \mathrm{L}$ and $\mathrm{C}$ are respectively the capacitances and inductances calculated: between the $\mathrm{m}$ th conductor and the reference for self-values, and, between $\mathrm{m}$-th and $\mathrm{n}$-th for the mutual values. $1_{\mathrm{mn}}$ and $\mathrm{b}_{\mathrm{mn}}$ can be calculated from the following equations :

$$
\begin{aligned}
& \mathrm{b}_{\mathrm{mn}}=\frac{1}{4 \pi \varepsilon} \int_{\mathrm{C}_{\mathrm{n}}} \frac{\mathrm{dI}_{\mathrm{n}}\left(\mathrm{z}^{\prime}\right) / \mathrm{dz} \mathrm{z}^{\prime}}{\mathrm{dI}_{\mathrm{n}}(\mathrm{z}) / \mathrm{dz}} \cdot[\Delta \mathrm{G}] \mathrm{dz} \mathrm{z}^{\prime} \\
& \mathrm{l}_{\mathrm{mn}}=\frac{\mu}{4 \pi} \int_{\mathrm{C}_{\mathrm{n}}} \frac{\mathrm{I}_{\mathrm{n}}\left(\mathrm{z}^{\prime}\right)}{\mathrm{I}_{\mathrm{n}}(\mathrm{z})} \hat{\mathrm{z}} \cdot \hat{\mathrm{z}}^{\prime} \cdot[\Delta \mathrm{G}] \mathrm{dz} \mathrm{z}^{\prime} \\
& \Delta \mathrm{G}=\left[\mathrm{G}_{\mathrm{mn}}\left(\mathrm{z}, \mathrm{z}^{\prime}\right)-\mathrm{G}_{\mathrm{m} 0}\left(\mathrm{z}, \mathrm{z}^{\prime}\right)-\mathrm{G}_{0 \mathrm{n}}\left(\mathrm{z}, \mathrm{z}^{\prime}\right)+\mathrm{G}_{00}\left(\mathrm{z}, \mathrm{z}^{\prime}\right)\right]
\end{aligned}
$$

Therefore, the characteristic impedance can be defined by the ratio of the forward-wave voltage and current. The line parameters obtained from (9) can be calculated by supposing $\operatorname{In}(\mathrm{z}) \approx \exp (-\mathrm{jkz})$, where $\mathrm{K}$ is the propagation constant in free-space.

\section{Application of the formalism to calculate P.U.L. parameters of a twisted pair cable}

Nowadays, as the high bit rate technology is widely used, the modelling of the twisted pair cable becomes essential to study the radiated electromagnetic fields. The shape of the twisted pair cable is modelled as a double helix (Figure $1)$.

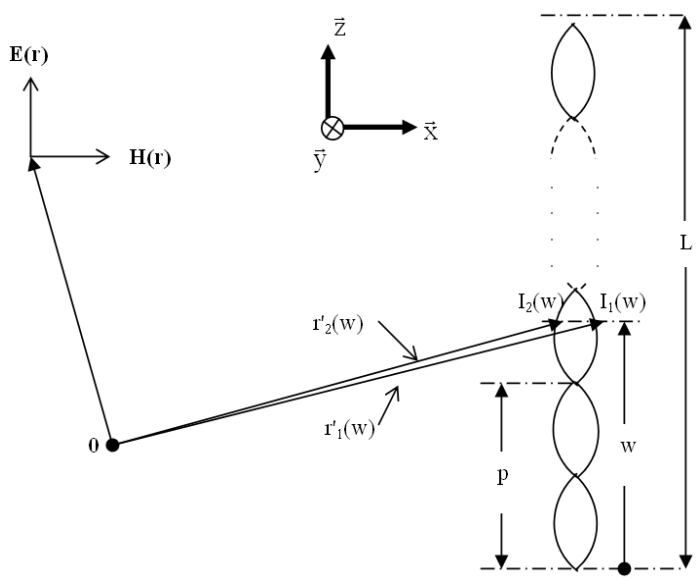

Fig. 1. The radiation from twisted pair cable

The Cartesian co-ordinates of a double helix (wire 1 and wire 2) in a three-dimensional space and directed according to Z-axis $[4,5]$ were considered :

$$
\begin{array}{ll}
\mathrm{X}_{1}=\delta \cdot\left(\frac{\mathrm{p}}{2 \cdot \pi}\right) \cdot \mathrm{w} & \mathrm{X}_{2}=\delta \cdot\left(\frac{\mathrm{p}}{2 \cdot \pi}\right) \cdot \mathrm{w} \\
\mathrm{Y}_{1}=\mathrm{R}^{\prime} \cdot \cos (\delta \cdot \mathrm{w}) & \mathrm{Y}_{2}=-\mathrm{R}^{\prime} \cdot \cos (\delta \cdot \mathrm{w}) \\
\mathrm{Z}_{1}=\mathrm{h}+\mathrm{R}^{\prime} \cdot \sin (\delta \cdot \mathrm{w}) & \mathrm{Z}_{2}=\mathrm{h}-\mathrm{R}^{\prime} \cdot \sin (\delta \cdot \mathrm{w}) \\
\text { Where, } \quad \delta=\left[\mathrm{R}^{\prime 2}+\left(\frac{\mathrm{p}}{2 \cdot \pi}\right)^{2}\right]^{-\frac{1}{2}}
\end{array}
$$

$R^{\prime}$ is the cable radius, $p$ is the cable pitch, i.e., the length of one turn, $\mathrm{L}$ is the physical length of the radiating part of the cable. Where $\mathrm{w}$ is the length parameter, $\mathrm{w}$ running from zero to $\mathrm{L}$. 
Using the theory of the electric images, $\mathrm{R}$ is the distance from the source to observation point. The $\mathrm{s}$ points are located on the conductor surface and the s' points are located on the axis of the structure:

$\mathrm{R}^{ \pm}=\sqrt{\left(\mathrm{s}-\mathrm{s}^{\prime}\right)^{2}+\mathrm{r}_{ \pm}^{2}}$

The symbols "+" indicate the distances $\mathrm{R}$ from the source to the observation point, on the other hand, the distances from the image of the source to the observation point are indicated by the symbols "-".

$r$ is also a distance which its value is related to coordinates of each pair $\left(\mathrm{X}_{1}, \mathrm{Y}_{1}, \mathrm{Z}_{1}\right.$ and $\left.\mathrm{X}_{2}, \mathrm{Y}_{2}, \mathrm{Z}_{2}\right)$.

By making a change of variables $x^{\prime}=-s$, the inductance and capacitance can be calculated as follows :

$$
\begin{aligned}
& \mathrm{l}(\mathrm{s})=\frac{\mu}{4 \pi} \theta\left(\mathrm{s}, \mathrm{X}_{1}, \mathrm{X}_{2}, \mathrm{Y}_{1}, \mathrm{Y}_{2}, \mathrm{Z}_{1}, \mathrm{Z}_{2}\right) \\
& \mathrm{c}(\mathrm{s})=\frac{4 \pi \varepsilon}{\theta\left(\mathrm{s}, \mathrm{X}_{1}, \mathrm{X}_{2}, \mathrm{Y}_{1}, \mathrm{Y}_{2}, \mathrm{Z}_{1}, \mathrm{Z}_{2}\right)}
\end{aligned}
$$

$\theta$ can be expressed as :

$$
\begin{aligned}
\theta=\{ & E_{i}\left[-j k \sqrt{s^{2}+r_{+}^{2}}-s\right] \\
& -E_{i}\left[-j k \sqrt{s^{2}+r_{-}^{2}}-s\right] \\
& -E_{i}\left[-j k \sqrt{(L+s)^{2}+r_{+}^{2}}-(L+s)\right] \\
& \left.+E_{i}\left[-j k \sqrt{(L+s)^{2}+r_{-}^{2}}-(L+s)\right]\right\}
\end{aligned}
$$

\section{A. Case of Unshielded Twisted Pair Cable}

The conductor geometry plays an essential role in the limitation of the interferences and the radiation phenomena. In the transmission line theory, this impact appears clearly in the P.U.L. matrices, through the values and the symmetry of every matrix [6].

The calculation of the P.U.L. parameters of multiconductor twisted pair cable is more constraining compared to of the case of flat conductors. The cables are above of infinite ground plane, where in X-coordinate $s=0$, the height of the axis of conductor " $n$ " is $h_{n}$. Using the theory of the electric images of UTP [1].

In order to validate the theoretical results, experimentations were carried out to measure values for unshielded cables network. Appendix (2) shows the simulation and measurement results of the average values of characteristic impedances $\left(Z_{c}\right)$.

However, we can observe a good tuning between the calculated and measured parameters, which shows the validity of our model.

\section{B. Case of Shielded Twisted Pair cable}

In the case of the STP cables, the images of the conductors are calculated and located at radial distances from the shield, as indicated in figure 2 [1].

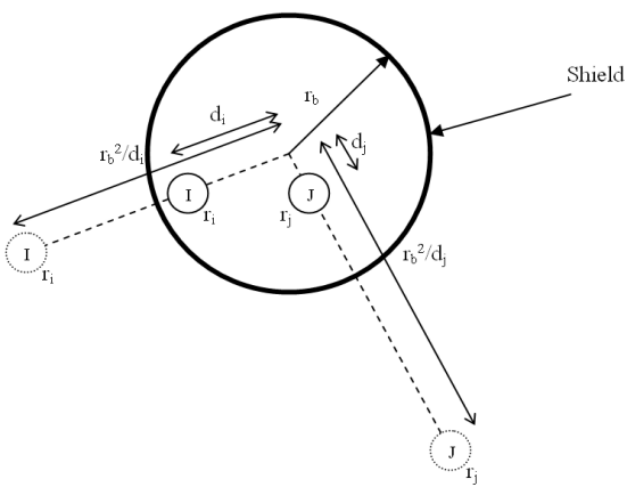

Fig. 2. Shielded twisted pair $s=0$, Using the theory of the electric images.

Let us note $r_{b}$ the radius of the shield, and, $d_{i}$ the distance which separates conductor " $\mathrm{j}$ " to the shield center. In the case of a circular shield, the image is at $r_{b}{ }^{2} / d_{j}$ from the center. The $Z_{c}$ parameters were measured [6], and then these results were compared with the calculated values. The symmetry in the P.U.L. matrix was reproduced correctly. Moreover, we noted a good agreement (Appendix (2), Table: 3,4$)$.

\section{Application of the formalism on transmission line network with discontinuities}

In this section, we will study the case of two conductors of radius "a" with an arbitrary angle $\alpha_{0}$ shown in figure 3 . The first conductor " $\mathrm{C}_{1}$ " is suspended at the height $\mathrm{h} 1$, however the second conductor " $\mathrm{C}_{2}$ " is at $\mathrm{h} 1$ in $\mathrm{s}=0$ and at $\mathrm{h} 2$ in $\mathrm{s}=\mathrm{L}_{2}$ over the ground plane.

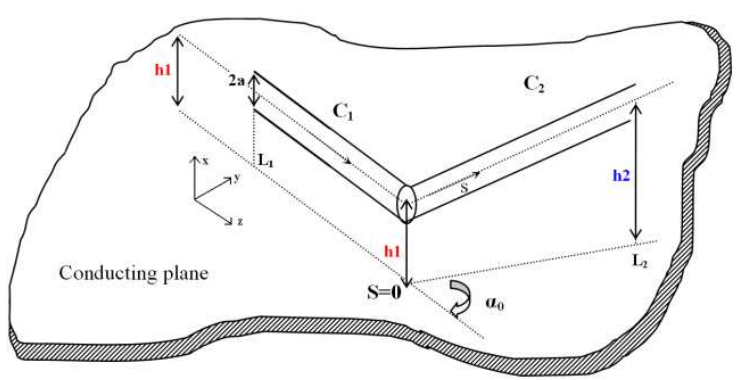

Fig. 3. Conductors with bend over ground Plane

Hence, from $(5,6)$ the series impedance $Z(s)$ and shunt admittance $\mathrm{Y}(\mathrm{s})$ can be expressed as follows:

$$
\begin{aligned}
& \mathrm{Z}(\mathrm{s})=\frac{\mathrm{j} \omega \mu}{4 \pi} \int_{\mathrm{C}} \frac{\mathrm{I}\left(\mathrm{s}^{\prime}\right)}{\mathrm{I}(\mathrm{s})}\left[\mathrm{G}_{11}\left(\mathrm{~s}, \mathrm{~s}^{\prime}\right) \mp \cos \alpha_{0} \mathrm{G}_{12}\left(\mathrm{~s}, \mathrm{~s}^{\prime}\right)\right] \mathrm{ds}^{\prime} \\
& \frac{1}{\mathrm{Y}(\mathrm{s})}=\frac{1}{4 \pi \mathrm{j} \omega \varepsilon} \int_{\mathrm{C}} \frac{\partial \mathrm{I}\left(\mathrm{s}^{\prime}\right) / \partial \mathrm{s}^{\prime}}{\partial \mathrm{I}(\mathrm{s}) / \partial \mathrm{s}}\left[\mathrm{G}_{11}\left(\mathrm{~s}, \mathrm{~s}^{\prime}\right) \pm \mathrm{G}_{12}\left(\mathrm{~s}, \mathrm{~s}^{\prime}\right)\right] \mathrm{ds}^{\prime}
\end{aligned}
$$

The integrals in (15) and (16) expression can be simplified be making a change of variables. The P.U.L. inductance $1\left(\mathrm{~s}, \mathrm{~h}_{\mathrm{i}}\right)$ and capacitance $\mathrm{c}\left(\mathrm{s}, \mathrm{h}_{\mathrm{i}}\right)$ of the line can be calculated by: 


$$
\begin{aligned}
& \mathrm{L}_{1} \leq \mathrm{s}<0 \Rightarrow \\
& \left\{\begin{array}{l}
h_{i}=h 1 \\
l\left(s, h_{i}\right)=\frac{\mu}{4 \pi}\left(A_{1}\left(s, h_{i}\right)+A_{2}\left(s, h_{i}\right) \cos \alpha_{0}\right) \\
c\left(s, h_{i}\right)=\frac{4 \pi \varepsilon}{\left(A_{1}\left(s, h_{i}\right)+A_{2}\left(s, h_{i}\right)\right)}
\end{array}\right.
\end{aligned}
$$

$$
\begin{aligned}
& 0 \leq \mathrm{s}<\mathrm{L}_{2} \Rightarrow \\
& \mathrm{h} 1 \leq \mathrm{h}_{\mathrm{i}} \leq \mathrm{h} 2 \\
& \mathrm{l}\left(\mathrm{s}, \mathrm{h}_{\mathrm{i}}\right)=\frac{\mu}{4 \pi}\left(\mathrm{A}_{3}\left(\mathrm{~s}, \mathrm{~h}_{\mathrm{i}}\right)+\mathrm{A}_{4}\left(\mathrm{~s}, \mathrm{~h}_{\mathrm{i}}\right) \cos \alpha_{0}\right) \\
& \mathrm{c}\left(\mathrm{s}, \mathrm{h}_{\mathrm{i}}\right)=\frac{4 \pi \varepsilon}{\left(\mathrm{A}_{3}\left(\mathrm{~s}, \mathrm{~h}_{\mathrm{i}}\right)+\mathrm{A}_{4}\left(\mathrm{~s}, \mathrm{~h}_{\mathrm{i}}\right)\right)}
\end{aligned}
$$

The $A_{1}, A_{2}, A_{3}$ and $A_{4}$ expression are respectively derived in the Appendix (1).

With the chain supermatrix, the values off all voltages and currents along the cable can be determined for each frequency. So, $\mathrm{v}(\mathrm{s})$ and $\mathrm{i}(\mathrm{s})$ are the voltage vector and current vector at abscissa $\mathrm{s}$.

To calculate the radiated fields, let us assume that the reference conductor is ideal (i.e. infinite and perfectly conducting ground plane). The electromagnetic field is calculated at a point $\mathrm{P}$ specified by its right-hand cartesian coordinate $(\mathrm{X}, \mathrm{Y}, \mathrm{Z})$.

Where $X$ is a vertical distance above the horizontal ground plane, $\mathrm{Y}$ is the distance from the cable, $\mathrm{Z}$ is a horizontal distance parallel to the cable. Consequently, the radiated emission by the cable above the ground plane is determined by the per-unit-length dipole moments (electric and magnetic dipole moment). Finally, the electric and magnetic fields respectively are calculated by using the Hertz potentials.

\section{A. Application case and results}

We consider as numerical application case: a bend two-wire transmission line over ground plane as shown in figure 4 .

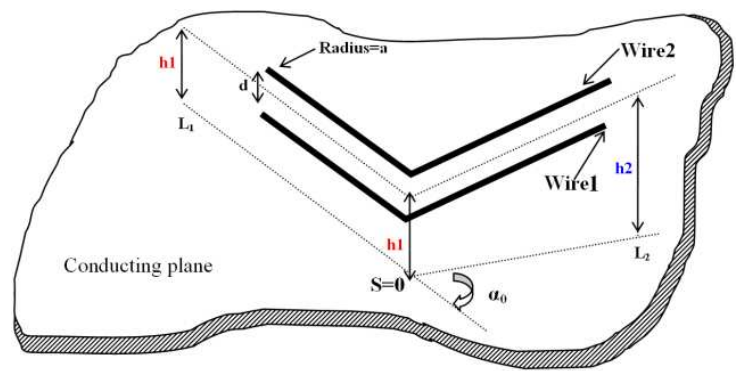

Fig. 4. Conductors with bend over ground plane

The height of conductors is constant $(\mathrm{h} 1=1 \mathrm{~m})$ for $\mathrm{L}_{1} \leq \mathrm{s}<0$, and, for $\mathrm{s}$ including between 0 and $\mathrm{L}_{2}$, this value is variable $\mathrm{h} 1 \leq \mathrm{h}_{\mathrm{i}} \leq \mathrm{h} 2(\mathrm{~h} 2=1.5 \mathrm{~m})$.

The first conductor (Wire1) is connected to a voltage source of unit amplitude and terminated by a resistance of $120 \Omega$. Wire 2 is connected to the ground at both ends.
In order for verify the applicability of the formulation, the results calculated by our approach will be compared to the results obtained by the antenna theory (FEKO code).

The electric fields were calculated at $\mathrm{P}=[50 \mathrm{~cm}, 1 \mathrm{~m}, 49 \mathrm{~m}]$. The results of $\mathrm{E}$ fields obtained with the two approaches are represented on the curves of figure 5.

In the same context, a simulation was carried out to study the magnetic field for the same network configuration (Figure 4). Once again, the field is calculated by the tow theories (antenna and non-uniform transmission line), figure 6 shows the magnetic radiated emission $(\mathrm{H})$.

However, we can observe a good tuning between the calculated the field results, which shows the validity of our model. The evolution of the signal level was reproduced correctly. The difference between simulations is due to the assumptions made in our theoretical approach.

\section{Conclusion}

In order to study the radiation from complex network of multiconductor transmission lines, a theoretical approach has been presented. The method is formulated in the frequency domain and uses multiconductor transmission line theory for the determination of field sources. This formalism is based on the modified transmission lines theory, where the P.U.L. parameters vary according to the geometry of the line.

Analytical expressions for P.U.L. parameters of twisted pair transmission lines have been developed and programmed with Matlab.

To validate the theoretical approach, the simulated results were compared with the measurements of P.U.L. parameters carried out in France Telecom laboratory. The obtained results confirm the assumptions used, and validate the model of simulation. The discrepancies between simulations and experimental results are due to; the inaccuracy of P.U.L. measurement and the assumptions made in the theoretical approach.

The distribution of the electromagnetic field radiated by cable network with discontinuity was simulated by using this formalism. Then, the results calculated by this theory were compared to those obtained by using a code based on the antennas theory. We noted a very good agreement between the two formalisms. The weak inaccuracy observed between the results is also attributed to due to the many assumptions used to simplify and decrease the calculation time.

The method can be used to study EMC phenomena for complex cables systems. In addition, an equivalent circuit can be defined to characterize the bends or other type of geometrical discontinuities. The study reported here may be useful in establishing the new engineering rules for the deployment of high bit rate data systems on coppers transmission systems. 

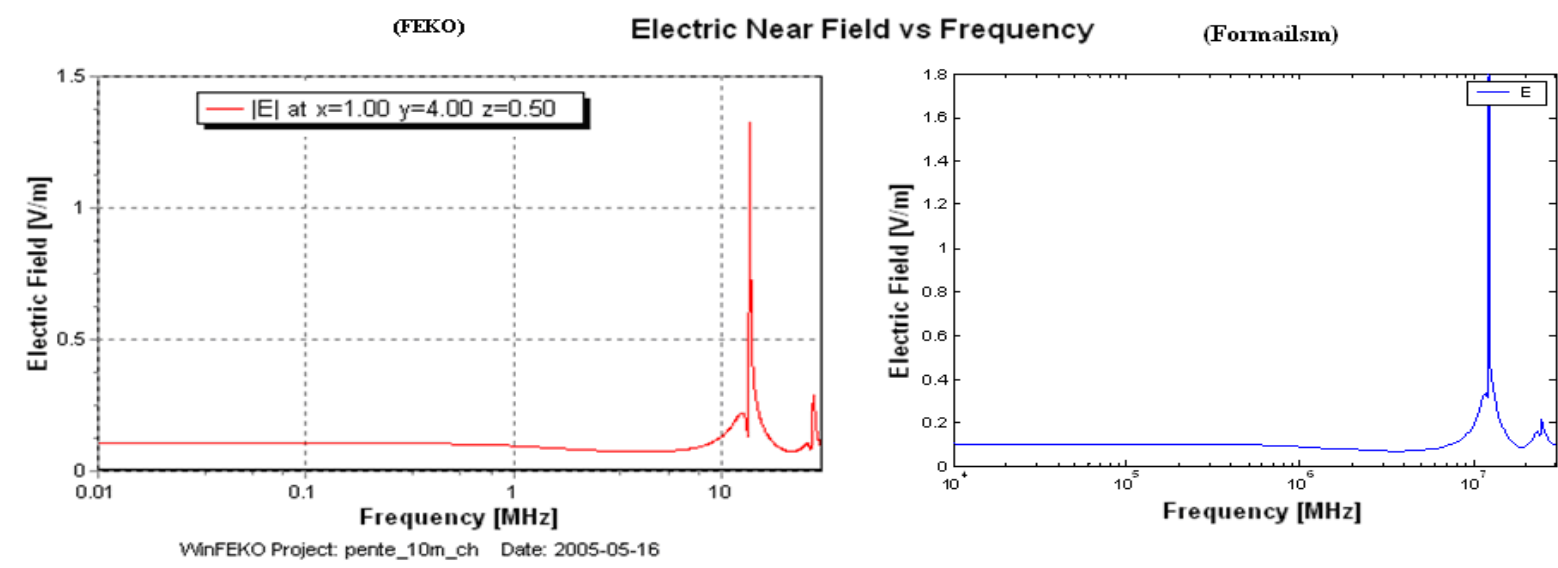

Fig. 5. Electric field (E) - Antenna/ Formalism, $P=[50 \mathrm{~cm}, 1 \mathrm{~m}, 4 \mathrm{~m}], \alpha_{0}=90^{\circ}, \mathrm{L}_{1}=\mathrm{L}_{2}=5 \mathrm{~m}$.

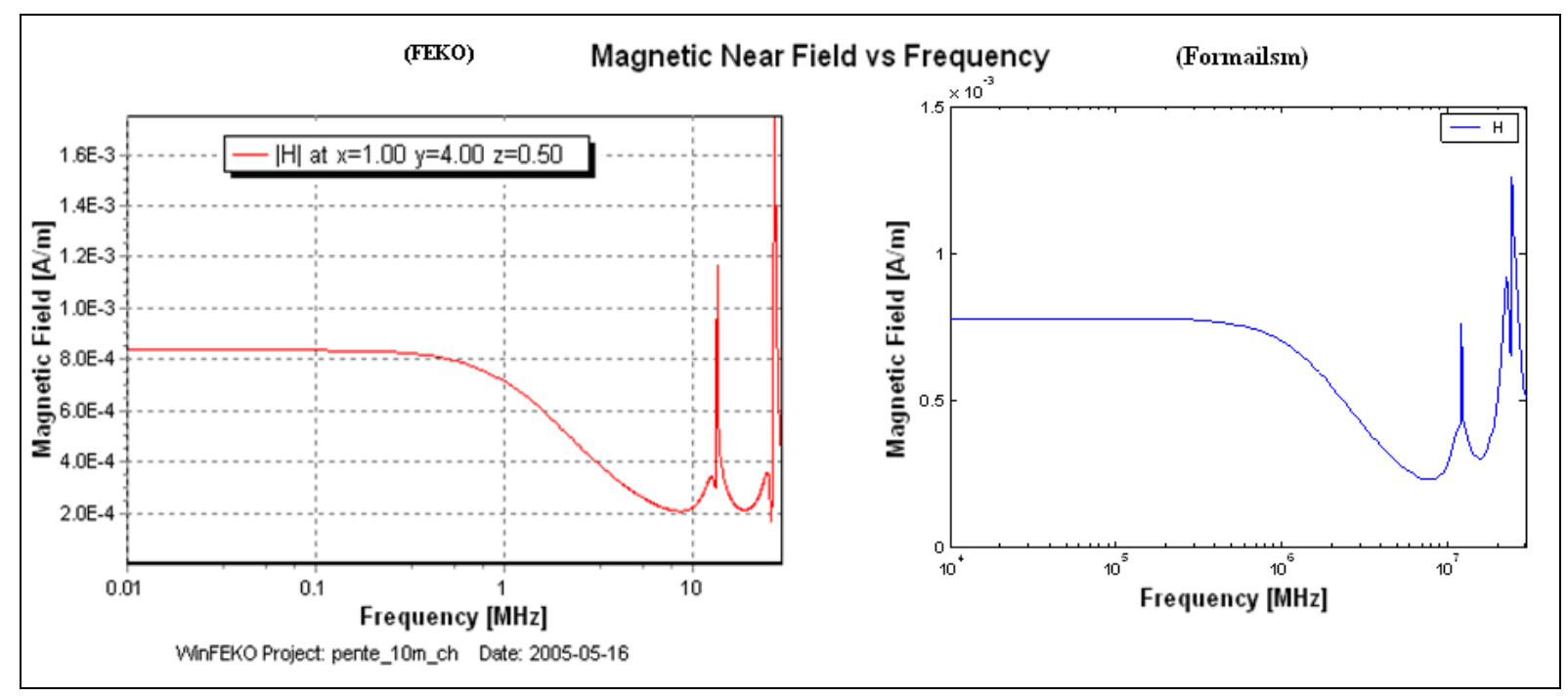

Fig. 6. Magnetic field $(\mathrm{H})-$ Antenna/ Formalism, $\mathrm{P}=[50 \mathrm{~cm}, 1 \mathrm{~m}, 4 \mathrm{~m}], \alpha_{0}=90^{\circ}, \mathrm{L}_{1}=\mathrm{L}_{2}=5 \mathrm{~m}$.

\section{References}

[1] Analysis of Multiconductor Transmission Lines, Clayton R. Paul, 1994 by John Wiley \& Sons, In.

[2] C. Gordon and K. M. Roselle, "Estimating crosstalk in multiconductor transmission lines," IEEE Trans. vol. 19, pp. 273 277, May 1996.

[3] R. F. Harrington, Field Computation by Moment Methods. Piscataway : IEEE, 1993, ch. 3.

[4] EMP-coupling to twisted-wire cables, S. Celozzi, M. Feliziani, University of Rome, ROME, Italy, IEEE 1999.
[5] Reinhard Stolle, "Electromagnetic Coupling of Twisted Pair Cables", IEEE VOL. 20, June 2002.

[6] Radiation from the transmission line with an acute bend, Nakamura, T.; Hayashi, N.; Fukuda, H.; Yokokawa, S.; IEEE , Aug. 1995.

[1] W. Shi and J. Fang, "Evaluation of closed-form crosstalk models ofcoupled transmission lines," IEEE Trans. vol. 22, pp.174-181, May 1999.

[7] F. HASSOUN, R. TARAFI, A. ZEDDAM "Calculation of PerUnit-Length parameters for shielded and unshielded twisted pair cables" EMC Zurich, Singapore, 2006. 


\section{$\underline{\text { Appendix (1) }}$}

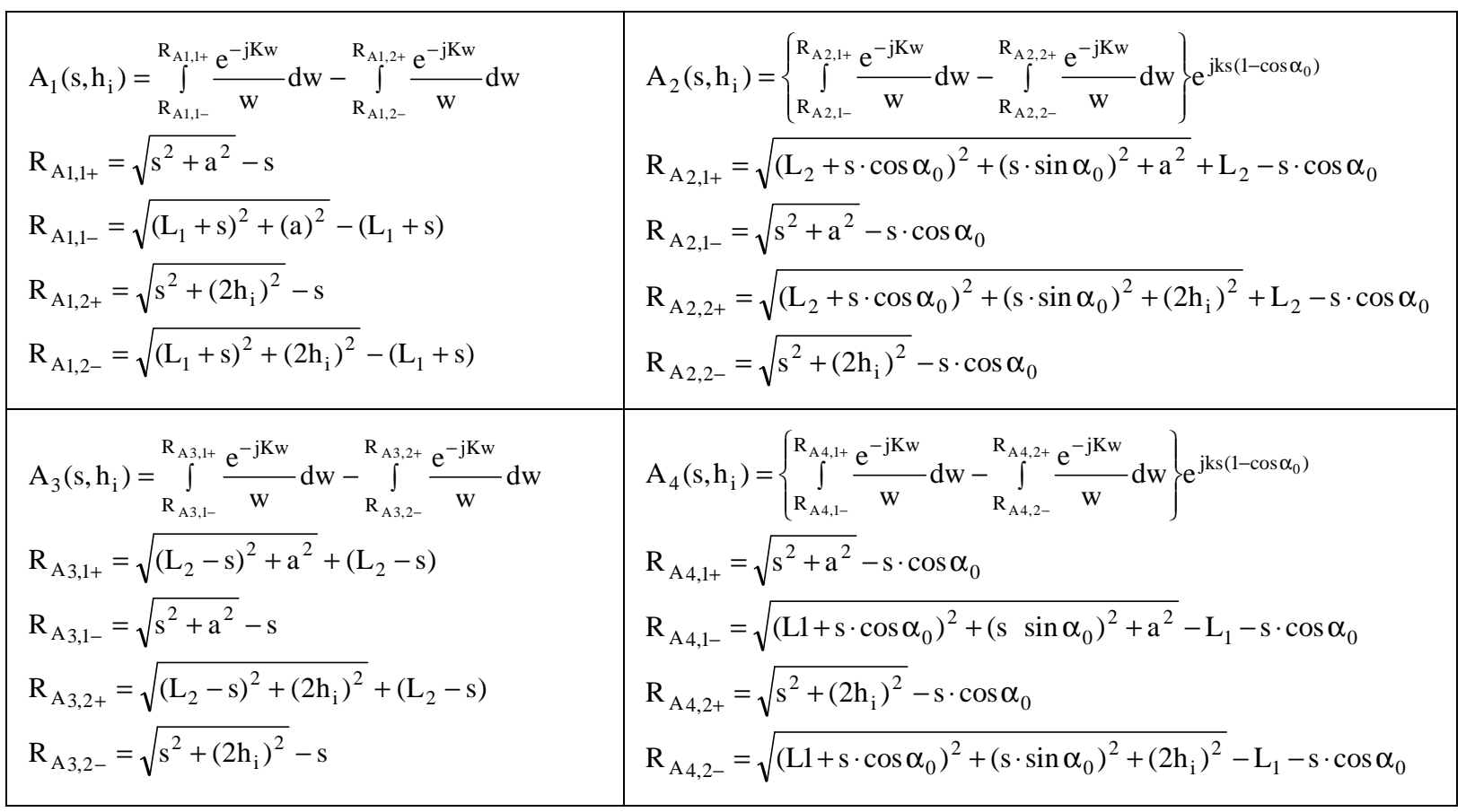

\section{$\underline{\text { Appendix (2) }}$}

Characteristic impedance: $Z_{c}=\sqrt{\frac{L}{C}}$

Unshielded twisted pair, 8 conductors, length $2 \mathrm{~m}$ height $0.5 \mathrm{~m}$, measureltheory

\begin{tabular}{|c|c|c|c|c|c|c|c|}
\hline \multicolumn{7}{|c|}{ Table 1 : Characteristic impedance measure (ohms) } \\
\hline 177,5 & 231,4 & 507,3 & 503,8 & 1051,6 & 1068,6 & 495,3 & 489,1 \\
\hline 231,4 & 176,8 & 506,5 & 502,0 & 1065,8 & 1052,0 & 501,8 & 497,5 \\
\hline 507,3 & 506,5 & 173,5 & 225,5 & 475,7 & 488,8 & 1023,2 & 1023,5 \\
\hline 503,8 & 502,0 & 225,5 & 174,5 & 489,6 & 488,8 & 1055,1 & 1120,1 \\
\hline 1051,6 & 1065,8 & 475,7 & 489,6 & 176,4 & 236,4 & 491,8 & 500,7 \\
\hline 1068,6 & 1052,0 & 488,8 & 488,8 & 236,4 & 176,4 & 495,0 & 495,7 \\
\hline 495,3 & 501,8 & 1023,2 & 1055,1 & 491,8 & 495,0 & 174,3 & 228,1 \\
\hline 489,1 & 497,5 & 1023,5 & 1120,1 & 500,7 & 495,7 & 228,1 & 174,4 \\
\hline
\end{tabular}

Table 2 : Characteristic impedance simulation (ohms)

\begin{tabular}{|l|l|l|l|l|l|l|l|}
\hline 176,8 & 213,9 & 550,1 & 514,3 & 916,3 & 874,7 & 543,9 & 541,8 \\
\hline 213,9 & 177,7 & 557,2 & 543,7 & 912,4 & 916,3 & 555,7 & 526,4 \\
\hline 550,1 & 557,2 & 177,5 & 213,9 & 526,2 & 541,6 & 894,1 & 924,7 \\
\hline 514,3 & 543,7 & 213,9 & 177,0 & 555,7 & 543,7 & 911,3 & 894,1 \\
\hline 916,3 & 912,4 & 526,2 & 555,7 & 177,7 & 213,9 & 543,7 & 557,2 \\
\hline 874,7 & 916,3 & 541,6 & 543,7 & 213,9 & 176,8 & 514,3 & 550,1 \\
\hline 543,9 & 555,7 & 894,1 & 911,3 & 543,7 & 514,3 & 177,0 & 213,9 \\
\hline 541,8 & 526,4 & 924,7 & 894,1 & 557,2 & 550,1 & 213,9 & 177,5 \\
\hline
\end{tabular}

Shielded twisted pair, 8 conductors, length $2 \mathrm{~m}$ height $0.5 \mathrm{~m}$, measure theory

Table 3 : Characteristic impedance measure (ohms)

\begin{tabular}{|c|c|c|c|c|c|c|c|}
\hline 84,3 & 95,5 & 174,1 & 170,9 & 367,7 & 366,1 & 160,6 & 156,8 \\
\hline 95,5 & 84,4 & 171,3 & 172,8 & 366,8 & 360,0 & 165,6 & 159,7 \\
\hline 174,1 & 171,3 & 87,3 & 83,5 & 161,9 & 162,3 & 263,5 & 267,5 \\
\hline 170,9 & 172,8 & 83,5 & 86,9 & 161,7 & 155,3 & 261,7 & 253,4 \\
\hline 367,7 & 366,8 & 161,9 & 161,7 & 88,7 & 90,6 & 155,1 & 153,8 \\
\hline 366,1 & 360,0 & 162,3 & 155,3 & 90,6 & 87,6 & 151,6 & 153,9 \\
\hline 160,6 & 165,6 & 263,5 & 261,7 & 155,1 & 151,6 & 88,9 & 86,0 \\
\hline 156,8 & 159,7 & 267,5 & 253,4 & 151,0 & 153,9 & 86,0 & 87,8 \\
\hline
\end{tabular}

Table 4 : Characteristic impedance simulation (ohms)

\begin{tabular}{|l|c|c|c|c|c|c|c|}
\hline 85,1 & 96,7 & 168,5 & 131,9 & 171,6 & 163,5 & 161,0 & 128,7 \\
\hline 96,7 & 79,6 & 129,6 & 161,8 & 167,5 & 143,7 & 125,8 & 152,8 \\
\hline 168,5 & 129,6 & 80,6 & 92,7 & 135,1 & 167,2 & 171,4 & 137,0 \\
\hline 131,9 & 161,8 & 92,7 & 80,6 & 186,5 & 127,4 & 137,4 & 175,0 \\
\hline 171,6 & 167,5 & 135,1 & 186,5 & 77,3 & 84,7 & 188,4 & 167,9 \\
\hline 163,5 & 143,7 & 167,2 & 127,4 & 84,7 & 82,4 & 236,1 & 330,0 \\
\hline 161,0 & 125,8 & 171,4 & 137,4 & 188,4 & 236,1 & 81,1 & 91,4 \\
\hline 128,7 & 152,8 & 137,0 & 175,0 & 167,9 & 330,0 & 91,4 & 81,1 \\
\hline
\end{tabular}

